\title{
New concepts in breast cancer genomics and genetics
}

Rodrigo Goncalves ${ }^{1,2,5}$, Wayne A Warner ${ }^{1,2,3,5}$, Jingqin Luo $2,4,5$ and Matthew J Ellis 1,2, $^{*}$

\begin{abstract}
Massively parallel DNA and RNA sequencing approaches have generated data on thousands of breast cancer genomes. In this review, we consider progress largely from the perspective of new concepts and hypotheses raised so far. These include challenges to the multistep model of breast carcinogenesis and the discovery of new defects in DNA repair through sequence analysis. Issues for functional genomics include the development of strategies to differentiate between mutations that are likely to drive carcinogenesis and bystander background mutations, as well as the importance of mechanistic studies that examine the role of mutations in genes with roles in splicing, histone methylation, and long non-coding RNA function. The application of genome-annotated patient-derived breast cancer xenografts as a potentially more reliable preclinical model is also discussed. Finally, we address the challenge of extracting medical value from genomic data. A weakness of many datasets is inadequate clinical annotation, which hampers the establishment of links between the mutation spectra and the efficacy of drugs or disease phenotypes. Tools such as dGene and the DGldb are being developed to identify possible druggable mutations, but these programs are a work in progress since extensive molecular pharmacology is required to develop successful 'genome-forward' clinical trials. Examples are emerging, however, including targeting HER2 in HER2 mutant breast cancer and mutant ESR1 in ESR1 endocrine refractory luminal-type breast cancer. Finally, the integration of DNA- and RNA-based sequencing studies with mass spectrometry-based peptide sequencing and an unbiased determination of post-translational modifications promises a more complete view of the biochemistry of breast cancer cells and points toward a new discovery horizon in our understanding of the pathophysiology of this complex disease.
\end{abstract}

\section{Introduction}

A decade after the first version of the human genome was published [1], annotation efforts continue, bringing us to the 19th revision, which is the current research standard. Analysis of protein-coding genes and their regulatory sequences is nearing completion, but these functions are served by only a small fraction of the genome. The rest is more functional than once thought, encoding, for example, many non-protein coding RNA genes with emerging regulatory and catalytic roles in cellular physiology and cancer [2]. Furthermore, mass spectrometry-based peptide sequencing is rapidly maturing, promoting studies that provide an unbiased analysis of information flowing from DNA to mRNA to protein

\footnotetext{
* Correspondence: mjellis@bcm.edu

'Breast Cancer Program, Department of Medical Oncology, Washington

University School of Medicine, 660 S. Euclid Ave, St Louis, MO 63110, USA

${ }^{2}$ Siteman Cancer Center, Washington University School of Medicine, 660

S. Euclid Ave, St Louis, MO 63110, USA

Full list of author information is available at the end of the article
}

to post-translational modification without the need for probes or antibodies at the individual gene or protein level [3]. Finally, deregulation of histone function and DNA methylation is readily evident in many tumor types and is a further consideration in cancer pathogenesis [4]. There is a growing chasm between our understanding of the breast cancer genome and our ability to translate these insights into improved patient outcomes. In this review, we present some of the most recent findings in the genomics field, from the biological discoveries emanating from genome sequencing studies to the clinical implications of those findings and finally to the future areas of potential research in the field.

\section{Recent biologically relevant findings in the genomics field}

Significantly mutated genes versus background mutations in breast cancer

Sequencing of DNA and RNA from tumors by using massively parallel sequencing with a capture or other 
sequence selection approach (exomes or candidate genes) or unbiased 'whole genome' approach has become a standard research tool now that the technology has been extensively commercialized [5-7]. One objective of cancer sequencing studies is to identify genes that have undergone somatic mutations, which contribute to malignant transformation. Genes that accumulate somatic mutations at a higher than stochastic rate are referred to as 'significantly mutated genes' (SMGs) and are considered likely drivers of malignant progression. In breast cancer, there is a dramatic difference in the SMG list between luminal-type breast cancer and basal-like breast cancer. In The Cancer Genome Atlas (TCGA) breast cancer data, at least 20 SMGs were observed in luminaltype A, eight in luminal-type B, but only three in basallike breast cancer (Table 1). This is not because luminal breast cancer genomes are more complex than those of basal-like breast cancer; in fact, the opposite is true. Basal-like breast cancer genomes are often so complex that it has proven difficult to identify the causal events by using mutation recurrence statistics. Furthermore, structural rearrangements (large-scale chromosomal deletions, amplifications, inversions, and translocations) are likely to play a particularly critical role in basal-like breast cancer, and the complete delineation of these events requires whole genome sequencing, which is technically demanding and expensive [8].

Detection of SMGs is complicated by the presence of a large number of likely irrelevant mutations referred to as 'background mutations' [9-11]. These occur not only in genes irrelevant to transformation but even within the SMGs themselves; that is, a missense mutation in a large tumor suppressor gene cannot be assumed to be always inactivating or cause dysfunction in the encoded protein. Mutant allele expression determined by RNA sequencing (RNA seq) is one starting point for disambiguating biologically relevant mutations on SMGs versus irrelevant ones. Many mutations detected at the DNA level are not expressed at the RNA level and thus, at least from the gain-of-function perspective, are unlikely to be major players in the carcinogenesis process [12]. Although there are challenges left to functionalize many of the SMGs as drivers of carcinogenesis, some progress has been made. RNA seq is widely used for the nomination and validation of expressed fusion genes and was recently used to define an endocrine therapy resistanceassociated ESR1 translocation [12]. Ultimately, functional studies are critical for resolving the role of mutations in certain SMGs versus background mutations, since the large number of mutations requiring annotation creates an extreme challenge, if this is done in an unbiased way [13]. An alternative approach is to be selective and initially study those associated with a therapeutic hypothesis. Another priority consists of the SMGs themselves, as the biology served by many of these, particularly those involved in mechanisms such as histone methylation, splicing, transcription, and long non-coding (lnc) RNA function is unclear. For example, whole genome analysis revealed clustered mutations in MALAT1, suggesting a gain-of-function role for this poorly understood and abundant lncRNA in breast cancer [14]. The functions of luminal SMGs have particularly striking similarities to drivers in hematopoietic malignancies [14], a link also emphasized by a recent study on the role of estradiol in hematopoiesis [15]. A particularly vexing problem is the functional resolution of mutated genes that drive pathogenesis in just a few patients or even in only one patient. A significant number of cases of luminal-type breast cancer in the TCGA analysis did not harbor a single SMG [16], suggesting that current genomic approaches would potentially benefit from additional refinement.

\section{The genomic structure of breast cancer reveals underlying DNA repair defects}

Aside from the focus on the identification of individual genes that are repetitively disrupted in breast cancer, a more broad-based analysis of breast cancer genome structures has led to a paradigm shift in the way we view pathogenesis. The standard multistep model of carcinogenesis postulates that mutations accumulate gradually, one at a time, in a process of Darwinian selection in which individual mutant-bearing clones effectively compete with normal cells and other clones within the tumor through the acquisition of the ability to transform, invade, metastasize, and evade drug treatment [17]. However, it was recently demonstrated that multiple mutations can arise over a very short period wherein multiple chromosomal breaks that occurred during a single catastrophic cell division event are (rarely) viably repaired, reshuffling the genome in a way that rapidly triggers transformation though the simultaneous oncogene amplifications and tumor suppressor gene deletions in the vicinity of the multiple translocations that ensue (chromothripsis) [18] (Figure 1). The reported frequency of chromothripsis in breast cancer varies from $2 \%$ to $11.06 \%$ [18,19]. Since chromothripsis and interval breast cancer are both marked by the suddenness of their appearance, we hypothesize that chromothripsis might explain the development of rapidly progressing, so-called 'interval', breast cancers that arise suddenly between screening visits. For this class of tumors, screening could never be effective as the time span of tumor development is too short. The genomic structure of interval breast cancers should be pursued aggressively as these tumors carry a high mortality burden. As more patients are included in clinical trials that include longitudinal genome sequencing of tumor samples, this hypothesis will be tested in the near future. 
Table 1 Significantly mutated genes based on all luminal versus basal-like breast cancers in The Cancer Genome Atlas dataset

\begin{tabular}{|c|c|c|c|c|c|c|c|c|c|}
\hline \multirow[t]{2}{*}{ Gene } & \multicolumn{3}{|c|}{ Luminal $A(n=225)$} & \multicolumn{3}{|c|}{ Luminal $B(n=126)$} & \multicolumn{3}{|l|}{ Basal-like $(n=93)$} \\
\hline & Number of cases & LRT & $\mathrm{CT}$ & Number of cases & LRT & CT & Number of cases & LRT & CT \\
\hline TP53 & 28 & 0 & 0 & 39 & 0 & 0 & 74 & 0 & 0 \\
\hline PIK3CA & 105 & 0 & 0 & 40 & 0 & 0 & 8 & $4.0 \times 10^{-6}$ & $3.4 \times 10^{-7}$ \\
\hline GATA3 & 32 & 0 & 0 & 19 & 0 & 0 & 2 & NA & NA \\
\hline MAP3K1 & 30 & 0 & 0 & 6 & $1.7 \times 10^{-8}$ & $4.7 \times 10^{-7}$ & 0 & NA & NA \\
\hline MLL3 & 19 & $1.5 \times 10^{-10}$ & $1.7 \times 10^{-11}$ & 7 & NA & NA & 6 & NA & NA \\
\hline $\mathrm{CDH} 1$ & 23 & 0 & 0 & 6 & $3.6 \times 10^{-3}$ & $6.6 \times 10^{-3}$ & 0 & NA & NA \\
\hline MAP2K4 & 16 & 0 & 0 & 3 & NA & NA & 0 & NA & NA \\
\hline RUNX1 & 13 & 0 & 0 & 3 & NA & NA & 0 & NA & NA \\
\hline PTEN & 9 & $4.3 \times 10^{-9}$ & $1.3 \times 10^{-11}$ & 6 & $3.7 \times 10^{-6}$ & $1.9 \times 10^{-7}$ & 1 & NA & NA \\
\hline TBX3 & 6 & $1.0 \times 10^{-6}$ & $2.7 \times 10^{-5}$ & 6 & $9.4 \times 10^{-5}$ & $1.4 \times 10^{-4}$ & 1 & NA & NA \\
\hline PIK3R1 & 4 & NA & NA & 4 & NA & NA & 2 & NA & NA \\
\hline AKT1 & 8 & $1.4 \times 10^{-11}$ & $3.2 \times 10^{-9}$ & 3 & NA & NA & 0 & NA & NA \\
\hline$C B F B$ & 5 & $4.2 \times 10^{-5}$ & $2.7 \times 10^{-5}$ & 2 & NA & NA & 0 & NA & NA \\
\hline TBLIXR1 & 5 & $2.9 \times 10^{-2}$ & $1.2 \times 10^{-3}$ & 1 & NA & NA & 0 & NA & NA \\
\hline NCOR1 & 12 & $3.8 \times 10^{-8}$ & $6.8 \times 10^{-9}$ & 3 & NA & NA & 2 & NA & NA \\
\hline CTCF & 9 & $8.8 \times 10^{-4}$ & $3.0 \times 10^{-6}$ & 2 & NA & NA & 1 & NA & NA \\
\hline ZFP36L1 & 2 & NA & NA & 4 & $1.3 \times 10^{-2}$ & $1.7 \times 10^{-2}$ & 1 & NA & NA \\
\hline GPS2 & 4 & $1.2 \times 10^{-3}$ & $6.0 \times 10^{-3}$ & 1 & NA & NA & 1 & NA & NA \\
\hline SF3B1 & 7 & $1.1 \times 10^{-6}$ & $5.3 \times 10^{-5}$ & 0 & NA & NA & 1 & NA & NA \\
\hline CDKN1B & 3 & $5.4 \times 10^{-3}$ & $1.9 \times 10^{-2}$ & 1 & NA & NA & 0 & NA & NA \\
\hline USH2A & 7 & NA & NA & 4 & NA & NA & 10 & NA & NA \\
\hline$R P G R$ & 2 & NA & NA & 2 & NA & NA & 4 & NA & NA \\
\hline$R B 1$ & 1 & NA & NA & 4 & NA & NA & 4 & $2.5 \times 10^{-2}$ & $4.8 \times 10^{-2}$ \\
\hline AFF2 & 3 & NA & NA & 3 & NA & NA & 4 & NA & NA \\
\hline NF1 & 6 & NA & NA & 5 & NA & NA & 2 & NA & NA \\
\hline PTPN22 & 1 & NA & NA & 3 & NA & NA & 0 & NA & NA \\
\hline RYR2 & 6 & NA & NA & 10 & NA & NA & 2 & NA & NA \\
\hline PTPRD & 4 & NA & NA & 5 & NA & NA & 1 & NA & NA \\
\hline OR6A2 & 2 & NA & NA & 1 & NA & NA & 0 & NA & NA \\
\hline HISTIH $2 B C$ & 1 & NA & NA & 1 & NA & NA & 1 & NA & NA \\
\hline GPR32 & 3 & $8.9 \times 10^{-3}$ & $4.3 \times 10^{-2}$ & 1 & NA & NA & 1 & NA & NA \\
\hline CLEC19A & 0 & NA & NA & 1 & NA & NA & 0 & NA & NA \\
\hline CCND3 & 2 & $1.5 \times 10^{-4}$ & $1.1 \times 10^{-3}$ & 0 & NA & NA & 0 & NA & NA \\
\hline SEPT13 & 2 & NA & NA & 0 & NA & NA & 1 & NA & NA \\
\hline DCAF4L2 & 1 & NA & NA & 3 & NA & NA & 1 & NA & NA \\
\hline
\end{tabular}

CT, chemotherapy; LRT, loco-regional treatment; NA, mutations observed were not considered statistically significant.

In another conceptual breakthrough, investigators at the Sanger Institute demonstrated that there are more than 20 different patterns of somatic mutation in cancer based on copy number aberrations and nucleotide substitution patterns, with a subset of these recurrently observed in breast cancer (APOBEC, BRCA1/2, Signature
B) [20]. Overexpression of cytidine deaminase APOBEC family members, in particular, has come into sharp focus. Clustered mutations characteristic of APOBEC activity have been particularly observed in and around chromosomal breakpoints, suggesting that single-stranded DNA generated during aberrant DNA repair is a substrate 


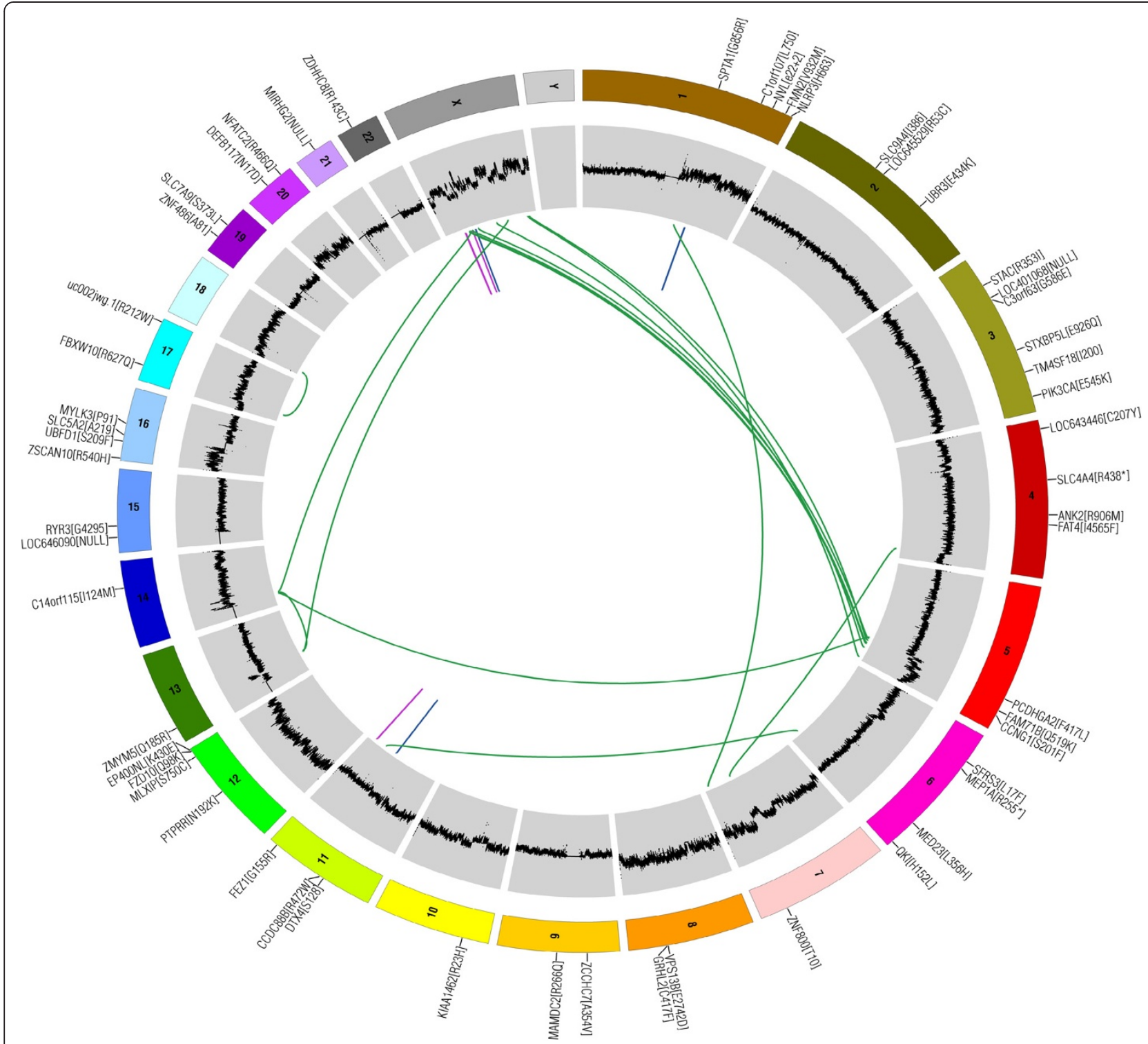

Figure 1 The presence of translocations and amplification at the ends of the breakpoints is evidence of chromothripsis in this Circos plot from a breast cancer sample. Chromothripsis scars the genome when localized chromosome shattering and repair occur in a one-off catastrophe.

for APOBEC enzymatic activity [21]. Differences in DNA repair defects explain the striking finding that some breast cancers display many more mutations than others [20,22]. Thus, even in the absence of a known SMG, it is possible to classify breast cancers on the basis of DNA repair defects and this could be clinically relevant. For example, clinical assays in development aim to identify tumors with defects in homologous recombination, which sensitize tumors to cytotoxic chemotherapy [23].

\section{Intra-tumor heterogeneity in breast cancer}

Chromothripsis, multistep progression, and defects in DNA repair combine to produce astonishing levels of both intra-tumoral and inter-tumoral heterogeneity in breast cancer. This complexity is an obvious explanation for the difficulty in curing breast cancer, particularly when advanced. As the tumor progresses and disseminates, the repertoire of biological possibilities encoded within billions of malignant cells, each subtly genetically different, means that resistance to targeted or more traditional cytotoxic therapy is almost inevitable. There is still not enough genomic data from multiple cancer samples from the same patient to track somatic mutation patterns from the primary through to metastatic disease and subsequent drug resistance. Longitudinal studies of this type, however, have been conducted successfully in 
individual cases. In 2009, Shah and colleagues [24] described the mutational evolution of a lobular breast carcinoma by using next-generation sequencing. Out of the 32 somatic, protein-coding mutations present in the metastasis, 19 could not be detected in the primary, five were prevalent in the primary, and six were present in the primary with a lower frequency. The Washington University group investigated the progression of a breast cancer to the brain at the whole genome level and found that the primary tumor and metastasis harbored approximately 48 somatic, protein-coding mutations [8]. In the metastatic sample, there were few de novo mutations, but higher variant allele frequencies and a few much lower, supporting a 'clonal remodeling' hypothesis for metastatic spread. At the single cell level of the tumor, various techniques have been used to directly visualize and quantify chromosomal aberrations, including duplications, deletions, and other distinctive chromosomal rearrangements. These studies show that breast cancers routinely exhibit genetic heterogeneity at preferred loci [25-29].

Evidence for marked tumor heterogeneity can be found in studies of other cancer types. For example, in a study of a renal cancer with metastasis to the lung and in the chest wall, sequencing of the metastases and nine different areas within the primary tumor found that only a third of mutations were common to all samples [30]. Based on these data, we can infer that heterogeneity and different subclones develop within the primary tumor, not all of which have the same metastatic potential. Metastases can develop early or late in each cancer's evolutionary history and are products of ongoing clonal evolution, which can be slow or very rapid. The ability to sequence individual cancer cells [31] will further illuminate this issue, although the complexity of the data analysis remains a considerable challenge.

\section{Clinical implications of genomic discoveries Clinical translation of massively parallel sequencing of DNA in breast cancer}

The sequencing of cancer with data return to the patient and physician is being piloted through 'genomic tumor boards' [32]. However, the complexity of the breast cancer genome has slowed progress, as has the relative paucity of obvious drug mutation matches [33]. Unlike drug therapy matched somatic mutations to melanoma and non-small cell lung cancer, drug therapy matched to the presence of a somatic mutation has yet to be robustly established as a standard approach in breast cancer. A number of strategies to increase the productivity and 'translatability' of DNA, RNA, and peptide sequencing studies in breast cancer should be considered. The initial set of sequencing-based studies in breast cancer revealed that this is one of the most heterogeneous forms of cancer, with the four commonly accepted subtypes (luminal-type A, luminal-type B, HER2-enriched, and basal-like) displaying distinct somatic mutation, gene copy, and epigenetic profiles [16]. Within the next few years, tens of thousands of primary breast cancers will likely be sequenced but often through clinical sequencing programs without a current systematic and broadbased plan to integrate the data with clinical endpoints. These studies risk following the course of the TCGA breast cancer study. While a technical tour de force, TCGA was largely a cross-platform genome-cataloging exercise and not a systematic clinical research addressing a particular problem in oncology [16]. Thus, it will not be possible to link the TCGA data to important clinical phenotypes such as drug response. Since polypharmacy is the rule in breast cancer treatment, establishing a link between mutational events and the efficacy of individual drugs is impossible unless a dedicated study is conducted. The neoadjuvant treatment setting allows ethical treatment plans with single agents as well as the acquisition of serial samples to assess the effect of treatment on breast cancer somatic genomes another subject in its infancy in breast cancer. Thus, a systematic approach linking high-quality sample acquisition, uniform neoadjuvant therapy regimens, and integrated 'omics' should be a high priority for clinical investigators. An example is provided by an integrated analysis of whole genome, exome-based somatic mutation detection, gene-expression, and gene copy profiles that identified molecular correlates of aromatase inhibitorresistant proliferation by using samples from a neoadjuvant study [14]. Mutations in TP53 were associated with endocrine therapy resistance, poor prognosis luminal-type $\mathrm{B}$ features, mutations in the stress kinase $M A P 3 K 1$ with low proliferation and luminal-type A features, and mutations in GATA3 with increased responsiveness to aromatase inhibition. A current research focus is to confirm these findings and to conduct additional studies with large sample sizes to link other breast cancer SMGs to clinical outcomes.

\section{The druggable breast cancer genome}

A major obstacle to the translation of newly defined genetic alterations into clinical benefit for patients lies in the identification of biologically relevant druggable aberrations that can be used as therapeutic targets [34]. To address this goal, programs such as dGene [35] and DGIdb [36] have been developed. The dGene program is an updated version of the druggable genome concept introduced in 2002 by Hopkins and Groom [37]. The druggable genome refers to a subset of genes that are known or predicted to interact with drugs. The software stratifies mutations from any database containing gene symbols into 10 different gene classes that are both potentially druggable and clinically relevant to cancer 
biology. An annotation and filtering tool is used to prioritize mutations for consideration. The analysis of a recent breast cancer genomic study [14] highlights the potential utility of this approach. From a total of 2,622 single-nucleotide variants identified in the neoadjuvant aromatase inhibitor discussed above, dGene identified 368 mutations out of 2,622 single-nucleotide variants as occurring in 255 druggable genes. When filtered for recurrence, that number was narrowed to 37 potentially druggable mutated genes present in at least two patients (Table 2). Despite its utility, dGene does not provide information on the type of mutation or guarantee clinical pertinence of mutations associated with any specific gene. This underscores the critical need to functionally test these and other genomic results.

A similar tool is DGIdb [36]. The concept behind the DGIdb is to classify gene mutations into two classes: genes that are known to have drug interactions and genes that are potentially druggable according to their gene category. DGIdb was developed by integrating data from 13 different sources and contains over 14,000 drug-gene interactions. It also includes 6,761 genes that belong to one or more of 39 potentially druggable gene categories. The utility of DGIdb was demonstrated by analyzing a cohort of 1,273 patients who were included in whole-genome or exome sequencing studies [16,38-41]. The software identified 6 of 31 genes (AKT1, CDH1, LRP2, PIK3CA, RYR2, and TP53) that were recurrently mutated in at least $2.5 \%$ of patients and also have known drug-gene interactions. With the addition of the top $1 \%$ of recurring mutations, the number of genes increased to 315. Six sources - DrugBank, MyCancerGenome, the Pharmacogenetics Knowledge Base (PharmGKB), Trends in the Exploitation of Novel Drug Targets (TEND), Targeted Agents in Lung Cancer (TALC), and Therapeutic Target Database (TTD) - were interrogated by DGldb to identify a total of 354 possible druggable gene interactions among the 315 genes. There was limited overlap between the sources, and only one drug-gene interaction was present in all six sources simultaneously (Figure 2a). The nature and extent of curation as well as the overall methodologies employed by each source are different (Figure 2a), which explains the limited overlap between the different sources. Some of the 315 genes are in potentially druggable categories (dGene), and others represent opportunities for drug discovery (Figure 2b).

This analysis serves to emphasize that these druggable genome approaches remain unvalidated by clinical trials and the pre-existing pharmacopeia is obviously inadequate, although 'drug repurposing' - the concept of redirecting US Food and Drug Administration-approved drugs to new secondary indications - is clearly an opportunity. Thus, in their current form, these computational approaches are mostly hypothesis-generating tools that are intended to accelerate medical research, not tools for clinical action (at least not yet). The next logical step after using such tools is to design functional studies to test the related drugs and find a more reliable answer as to whether such mutations are drivers of carcinogenesis or just background mutations.

\section{HER2 and ESR1 mutations as examples of novel druggable targets}

The utility of detailed preclinical work on potentially druggable genes is nicely illustrated by the study of HER2 mutations in breast cancer. Data from eight breast cancer genome-sequencing studies identified 25 patients with HER2 somatic mutations without HER2 amplification [14,16,24,38-42]. Thirteen HER2 mutations were functionally characterized by using in vitro kinase assays, protein structure analysis, cell culture, and xenograft experiments [43]. The results showed that the investigational drug neratinib, an irreversible HER2 inhibitor, rather than lapatinib, an approved HER2 kinase inhibitor, was a better approach for clinical studies since some of the recurrent mutations were naturally lapatinibresistant. This is a result that simple drug somatic mutation matching software would not have revealed. Currently, patients with advanced HER2 mutation-positive tumors are being enrolled into a single-agent study of neratinib (NCT01670877). Point mutations in the estradiol-binding domain of the estrogen receptor gene (ESR1) are emerging as a potent cause of acquired endocrine therapy resistance. Although there are no drugs that specifically target these mutations, alternative endocrine therapies may be effective in this setting $[44,45]$ and this possibility will soon be addressed in clinical trials.

\section{Patient-derived xenografts as genomic models for breast cancer}

A major criticism of standard cell lines as a model for human breast cancer is that they are essentially disconnected from the individuals from whom they were derived. Without knowledge of the progenitor tumor genome as a reference point and no knowledge of the clinical characteristics of the patient who donated the tissue, it is uncertain what the cell lines actually model from an individual patient perspective and to what degree genetic drift has occurred after prolonged in vitro culture. These limitations likely contribute to the poor predictive utility of cell line panels in drug development [46-48]. An alternative preclinical model for drug optimization and target validation is the patient-derived xenograft (PDX) approach. Detailed information covering the continuum from specimen acquisition to development of patient-derived xenografts has been presented and 
Table 2 Categorization of single-nucleotide variants in 77 breast cancer tumors using dGene: 37 dGene entries present in at least 2 out of 77 samples, organized by class and patients affected

\begin{tabular}{|c|c|c|c|}
\hline NCBI symbol & Full name & dGene class & Patients affected \\
\hline CASR & Calcium-sensing receptor & G protein-coupled receptor & 3 \\
\hline GPR112 & G protein-coupled receptor 112 & G protein-coupled receptor & 3 \\
\hline AGTR2 & Angiotensin II receptor, type 2 & $\mathrm{G}$ protein-coupled receptor & 2 \\
\hline MC5R & Melanocortin 5 receptor & G protein-coupled receptor & 2 \\
\hline OR2L2 & Olfactory receptor, family 2 , subfamily L, member 2 & G protein-coupled receptor & 2 \\
\hline OR51B5 & Olfactory receptor, family 51 , subfamily B, member 5 & G protein-coupled receptor & 2 \\
\hline PIK3CA & Phosphoinositide-3-kinase, catalytic, alpha polypeptide & $\mathrm{PI} 3 \mathrm{~K}$ & 37 \\
\hline BIRC6 & Baculoviral IAP repeat containing 6 & Proteinase inhibitor & 4 \\
\hline CPAMD8 & C3 and PZP-like, a-2-macroglobulin domain containing 8 & Proteinase inhibitor & 3 \\
\hline COL28A1 & Collagen, type XXVIII, alpha 1 & Proteinase inhibitor & 2 \\
\hline COL6A3 & Collagen, type VI, alpha 3 & Proteinase inhibitor & 2 \\
\hline AGBL1 & ATP/GTP binding protein-like 1 & Protease & 2 \\
\hline CPVL & Carboxypeptidase, vitellogenic-like & Protease & 2 \\
\hline PCSK5 & Proprotein convertase subtilisin/kexin type 5 & Protease & 2 \\
\hline RELN & Reelin & Protease & 2 \\
\hline SENP7 & SUMO1/sentrin specific peptidase 7 & Protease & 2 \\
\hline USP9X & Ubiquitin specific peptidase 9, X-linked & Protease & 2 \\
\hline PTPRF & Protein tyrosine phosphatase, receptor type, F & Phosphatase & 2 \\
\hline PTPRU & Protein tyrosine phosphatase, receptor type, U & Phosphatase & 2 \\
\hline $\mathrm{SSH} 3$ & Slingshot homolog 3 (Drosophila) & Phosohatase & 2 \\
\hline MAP3K1 & Mitogen-activated protein kinase kinase kinase 1 & Serine theonine kinase & 9 \\
\hline TTN & Titin & Serine theonine kinase & 6 \\
\hline ATR & Ataxia telangiectasia and Rad3 related & Serine theonine kinase & 5 \\
\hline OBSCN & Obscurin & Serine theonine kinase & 3 \\
\hline SMG1 & Smg-1 homolog & Serine theonine kinase & 3 \\
\hline ALPK2 & Alpha-kinase 2 & Serine theonine kinase & 2 \\
\hline BRAF & V-raf murine sarcoma viral oncogene homolog B1 & Serine theonine kinase & 2 \\
\hline DCLK3 & Doublecortin-like kinase 3 & Serine theonine kinase & 2 \\
\hline LRRK2 & Leucine-rich repeat kinase 2 & Serine theonine kinase & 2 \\
\hline MAP2K4 & Mitogen-activated protein kinase kinase 4 & Serine theonine kinase & 2 \\
\hline TAF1L & TATA box binding protein (TBP)-associated factor & Serine theonine kinase & 2 \\
\hline TBK1 & TANK-binding kinase 1 & Serine theonine kinase & 2 \\
\hline ULK4 & Unc-51-like kinase 4 & Serine theonine kinase & 2 \\
\hline INSRR & Insulin receptor-related receptor & Tyrosine kinase & 3 \\
\hline KIT & C-kit & Tyrosine kinase & 2 \\
\hline PDGFRA & Platelet-derived growth factor receptor & Tyrosine kinase & 2 \\
\hline TEX14 & Testis expressed 14 & Tyrosine kinase & 2 \\
\hline
\end{tabular}

NCBI, National Center for Biotechnology Information.

reviewed elsewhere [8,49-52]. In brief, a biopsy-sized sample of primary or metastatic tumor is transferred directly into an immunodeficient mouse by orthotopic or subcutaneous implantation. Once tumor engraftment has occurred, RNA and DNA sequencing or chip-based analysis is employed to compare the patient tumor to the PDX. PDXs maintain fidelity to the patient tumor based on molecular subtypes, mutational spectrum, copy number variations, gene expression profiles, and histopathology [50,53-56]. PDX models faithfully recapitulate the 
(a)

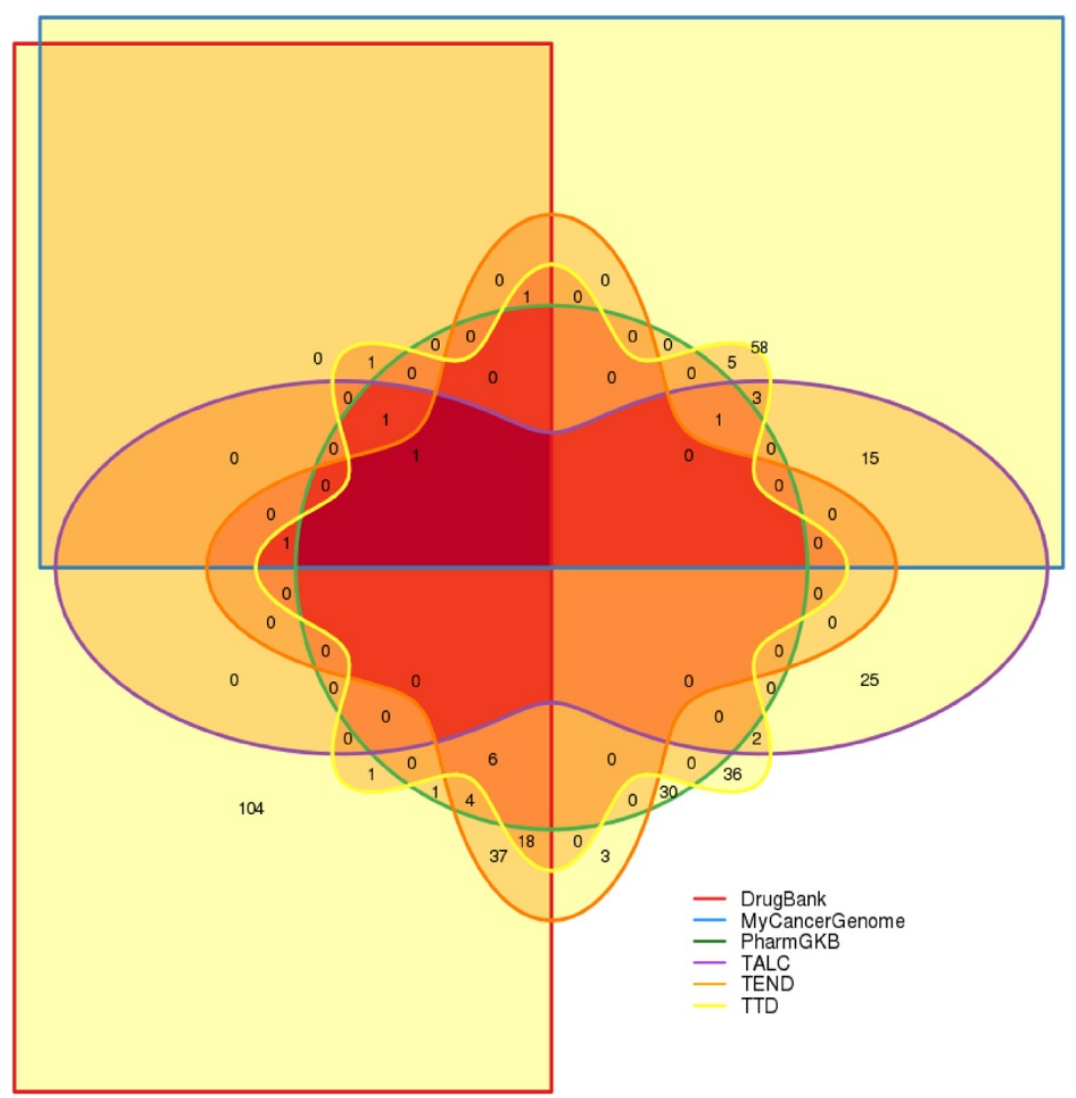

(b)

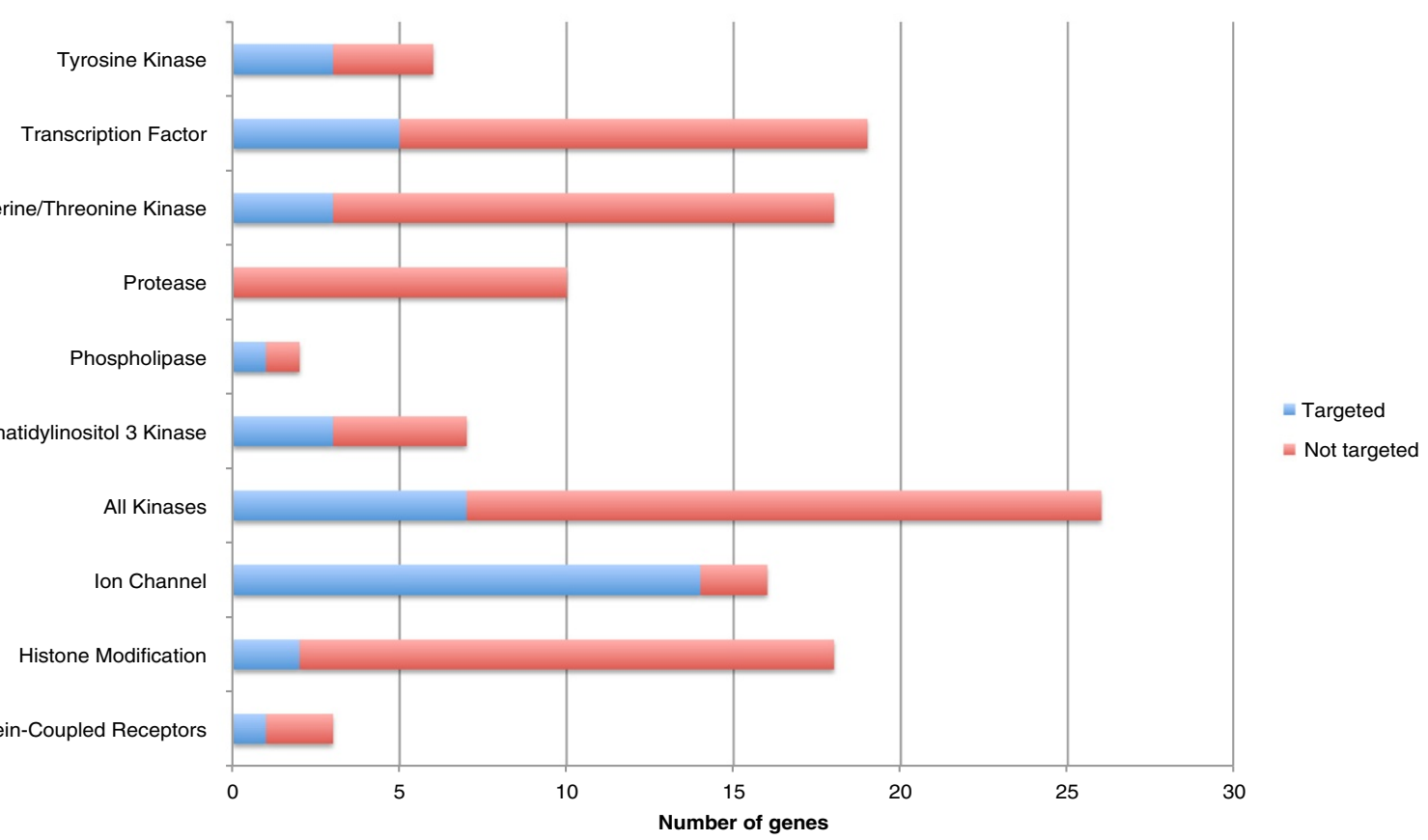

Figure 2 Druggability of significantly mutated gene (SMG) in breast cancer. (a) Overlap between six sources that generated a list of 354 possible drug-gene interactions among 315 genes recurrently mutated in breast cancer patients and analyzed by DGldb. One hundred and seventy-six drug-gene interactions were identified by DrugBank, 87 by MyCancerGenome, 77 by Therapeutic Target Database (TTD), 71 by Trends in the Exploitation of Novel Drug Targets (TEND), 49 by Targeted Agents in Lung Cancer (TALC), and 44 by the Pharmacogenetics Knowledge Base (PharmGKB). (b) Distribution of 315 genes in potentially druggable categories (from dGene) and the numbers of genes in these categories that are targeted by a known drug. 
intra-tumor heterogeneity and response to chemotherapy [53]. This close resemblance between the PDXs and the patient tumor makes it a suitable predictive preclinical model. The deployment of PDXs therefore can be considered a 'test bed' for personalized precision medicine in which genome-forward hypotheses can be assessed preclinically. However, despite the great promise and utility of PDXs, there are some drawbacks that need to be resolved to ensure wider adoption and improved utility. The limitations are the higher comparative cost, high level of technical expertise needed, the lack of an immune system, the effect of differences between the mouse and human microenvironment, and the degree of genetic drift and how this affects conclusions regarding biological and pharmacological findings.

Even with the mentioned limitations, the PDX model has great utility in breast cancer research. Through the genome sequencing of different PDX lines, $\mathrm{Li}$ and colleagues [12] identified new ESR1 point mutations and translocations. These gene mutations and the ESR1-YAP1 gene fusion were further investigated through functional studies that directly implicated them in resistance to treatment. Not coincidentally, the patients from whom these PDXs were derived presented with endocrine treatment resistance during their course of treatment.

\section{Future areas of research}

\section{Proteomics as the next step in the annotation of the breast cancer genome}

A fundamental problem in the study of cancer genomics at the level of DNA and RNA is that conclusions regarding pathway activation are indirect since proteins, not nucleic acids, execute these functions. Thus, when signaling and biology are discussed, it is through inference from signal transduction databases that may or may not have been conducted in the relevant biological context and that may or may not be correct. Informatics approaches generate hypotheses, not conclusions $[57,58]$. The reverse phase protein array (RPPA) is one answer to the problem of efficiently tracking protein levels and phosphorylation events [59]. Here, tumor protein extracts from many tumors are spotted into slides and probed with highly quality-controlled antibodies. Unfortunately, the generation of RPPA-quality antibodies is technically challenging; in particular, the number of phosphosite-specific antibodies is very limited. Therefore, mass spectrometry is being developed to examine the protein biochemistry of the cancer cells in less biased ways by direct protein sequencing and mass analysis to determine post-translational modifications [3]. Next-generation proteomic technologies are poised to provide deep information on tumor proteomes and on post-translational modifications of all types. When combined with genomic data, proteomics may enable a deeper understanding of complex mechanisms that regulate gene function and dysfunction in cancer. These objectives are being realized by the National Cancer Institute Clinical Proteomic Tumor Analysis Consortium, which is applying standardized proteome analysis platforms to analyze tumor tissues from the TCGA program as well as unique cell and xenograft models and other tissue collections, all of which are accompanied by rich genomic datasets [60].

\section{Conclusions}

The expansion of knowledge in genomics is already having a profound effect on breast cancer research and increasingly on treatment. It is clear, however, that genomesequencing studies have still not been adequately designed to address specific questions in breast cancer oncology. This is essential to translate the comprehensive catalog of recurrent mutations in breast cancer to a functionally and pharmacologically annotated treatment road map. Through the sequencing of tumors in different time-points, we will be able to identify cellular pathways and targets for drug development and use this information for the development of clinically testable hypotheses. Integrated approaches that not only account for DNA and RNA aberrations but also document protein function and biochemistry are clearly the next technical horizon [60].

\section{Abbreviations \\ AKT1: v-akt murine thymoma viral oncogene homolog1; APOBEC: Apolipoprotein B mRNA editing enzyme, catalytic polypeptide-like; BRCA1: Breast cancer 1, early onset; BRCA2: Breast cancer 2, early onset; $\mathrm{CDH1}$ : Cadherin 1, type 1, E-cadherin (epithelial); ESR1: Estrogen receptor 1; GATA3: GATA binding protein 3; HER2: Human epidermal growth factor receptor 2; Inc: Long non-coding; LRP2: Low density lipoprotein receptor-related protein 2; MALAT1: Metastasis associated lung adenocarcinoma transcript 1; MAP3K1: Mitogen-activated protein kinase kinase kinase 1, E3 ubiquitin protein ligase; PDX: Patient- derived xenograft; PIK3CA: Phosphatidylinositol-4,5-bisphosphate 3-kinase, catalytic subunit alpha; RNA seq: RNA sequencing; RPPA: Reverse phase protein array; RYR2: Ryanodine receptor 2 (cardiac); SMG: Significantly mutated gene; TCGA: The cancer genome Atlas; TP53: Tumor protein p53.}

\section{Competing interests}

MJE declares patent and royalty income from BioClassifier LLC (St Louis, MO, USA) through a license on the PAM50 patents to Nanostring (Seattle, WA, USA) for the intrinsic subtype test 'Prosigna'. The other authors declare that they have no competing interests.

\section{Authors' contributions}

All the authors made substantial contributions to the conception and design of this article, participated in drafting the article or revising it critically for important intellectual content, and gave final approval of the version submitted.

\section{Acknowledgments}

RG was supported by a grant from the AVON Foundation for Women. WAW was supported by Washington University School of Medicine, Graduate School of Arts \& Sciences/CGFP Fund 94028C. JL was supported by a Siteman Cancer Center Support Grant (P30CA091842). MJE was supported by Susan G. Komen for the Cure (PG12220321), the Clinical Proteomic Tumor Analysis Consortium (U24 CA160035 and R01 CA095614), the AVON Foundation for Women, a Siteman Cancer Center Support Grant (P30CA091842), and the Breast Cancer Research Foundation. 


\section{Author details}

${ }^{1}$ Breast Cancer Program, Department of Medical Oncology, Washington University School of Medicine, 660 S. Euclid Ave, St Louis, MO 63110, USA ${ }^{2}$ Siteman Cancer Center, Washington University School of Medicine, 660 S. Euclid Ave, St Louis, MO 63110, USA. ${ }^{3}$ Department of Cell Biology and Physiology, Washington University, 660 S. Euclid Ave, St Louis, MO 63110, USA. ${ }^{4}$ Division of Biostatistics, Washington University School of Medicine, 660 S. Euclid Ave, St Louis, MO 63110, USA. ${ }^{5}$ Lester and Sue Smith Breast Center, Baylor College of Medicine, One Baylor Plaza, 320A Cullen MS600, Houston, TX 77030, USA.

\section{Published online: 23 October 2014}

\section{References}

1. Lander ES, Linton LM, Birren B, Nusbaum C, Zody MC, Baldwin J, Devon K, Dewar K, Doyle M, FitzHugh W, Funke R, Gage D, Harris K, Heaford A, Howland J, Kann L, Lehoczky J, LeVine R, McEwan P, McKernan K, Meldrim J, Mesirov JP, Miranda C, Morris W, Naylor J, Raymond C, Rosetti M, Santos R, Sheridan A, Sougnez C, Stange-Thomann N, et al: Initial sequencing and analysis of the human genome. Nature 2001, 409:860-921.

2. ENCODE Project Consortium: The ENCODE (ENCyclopedia Of DNA Elements) Project. Science 2004, 306:636-640.

3. Ellis MJ, Perou CM: The genomic landscape of breast cancer as a therapeutic roadmap. Cancer Discov 2013, 3:27-34.

4. Tsai HC, Baylin SB: Cancer epigenetics: linking basic biology to clinical medicine. Cell Res 2011, 21:502-517.

5. Mardis ER: Genome sequencing and cancer. Curr Opin Genet Dev 2012, 22:245-250.

6. Koboldt DC, Steinberg KM, Larson DE, Wilson RK, Mardis ER: The next-generation sequencing revolution and its impact on genomics. Cell 2013, 155:27-38

7. Mutz KO, Heilkenbrinker A, Lönne M, Walter JG, Stahl F: Transcriptome analysis using next-generation sequencing. Curr Opin Biotechnol 2013, 24:22-30.

8. Ding L, Ellis MJ, Li S, Larson DE, Chen K, Wallis JW, Harris CC, McLellan MD, Fulton RS, Fulton LL, Abbott RM, Hoog J, Dooling DJ, Koboldt DC, Schmidt H, Kalicki J, Zhang Q, Chen L, Lin L, Wendl MC, McMichael JF, Magrini VJ, Cook L, McGrath SD, Vickery TL, Appelbaum E, Deschryver K, Davies S, Guintoli T, Lin L, et al: Genome remodelling in a basal-like breast cancer metastasis and xenograft. Nature 2010, 464:999-1005.

9. Vogelstein B, Papadopoulos N, Velculescu VE, Zhou S, Diaz LA Jr, Kinzler KW: Cancer genome landscapes. Science 2013, 339:1546-1558

10. Kalari S, Pfeifer GP: Identification of driver and passenger DNA methylation in cancer by epigenomic analysis. Adv Genet 2010, 70:277-308.

11. Bignell GR, Greenman CD, Davies H, Butler AP, Edkins S, Andrews JM, Buck G, Chen L, Beare D, Latimer C, Widaa S, Hinton J, Fahey C, Fu B, Swamy S, Dalgliesh GL, Teh BT, Deloukas P, Yang F, Campbell PJ, Futreal PA, Stratton MR: Signatures of mutation and selection in the cancer genome. Nature 2010, 463:893-898

12. Li S, Shen D, Shao J, Crowder R, Liu W, Prat A, He X, Liu S, Hoog J, Lu C, Ding L, Griffith OL, Miller C, Larson D, Fulton RS, Harrison M, Mooney T, McMichael JF, Luo J, Tao Y, Goncalves R, Schlosberg C, Hiken JF, Saied L, Sanchez C, Giuntoli T, Bumb C, Cooper C, Kitchens RT, Lin A, et al: Endocrine-therapy-resistant ESR1 variants revealed by genomic characterization of breast-cancer-derived xenografts. Cell Rep 2013, 4:1116-1130.

13. Liu ET: Functional genomics of cancer. Curr Opin Genet Dev 2008, 18:251-256.

14. Ellis MJ, Ding L, Shen D, Luo J, Suman VJ, Wallis JW, Van Tine BA, Hoog J, Goiffon RJ, Goldstein TC, Ng S, Lin L, Crowder R, Snider J, Ballman K, Weber J, Chen K, Koboldt DC, Kandoth C, Schierding WS, McMichael JF, Miller CA, Lu C, Harris CC, McLellan MD, Wendl MC, DeSchryver K, Allred DC, Esserman $L$, Unzeitig $G$, et al: Whole-genome analysis informs breast cancer response to aromatase inhibition. Nature 2012, 486:353-360.

15. Nakada D, Oguro H, Levi BP, Ryan N, Kitano A, Saitoh Y, Takeichi M, Wendt GR, Morrison SJ: Oestrogen increases haematopoietic stem-cell self-renewal in females and during pregnancy. Nature 2014, 505:555-558.

16. Network CGA: Comprehensive molecular portraits of human breast tumours. Nature 2012, 490:61-70.

17. Nowell PC: The clonal evolution of tumor cell populations. Science 1976, 194:23-28.

18. Stephens PJ, Greenman CD, Fu B, Yang F, Bignell GR, Mudie LJ, Pleasance ED, Lau KW, Beare D, Stebbings LA, McLaren S, Lin ML, McBride DJ, Varela I,
Nik-Zainal S, Leroy C, Jia M, Menzies A, Butler AP, Teague JW, Quail MA, Burton J, Swerdlow H, Carter NP, Morsberger LA, lacobuzio-Donahue C, Follows GA, Green AR, Flanagan AM, Stratton MR, et al: Massive genomic rearrangement acquired in a single catastrophic event during cancer development. Cell 2011, 144:27-40

19. Cai H, Kumar N, Bagheri HC, von Mering C, Robinson MD, Baudis M: Chromothripsis-like patterns are recurring but heterogeneously distributed features in a survey of 22,347 cancer genome screens. BMC Genomics 2014, 15:82.

20. Nik-Zainal S, Alexandrov LB, Wedge DC, Van Loo P, Greenman CD, Raine K, Jones D, Hinton J, Marshall J, Stebbings LA, Menzies A, Martin S, Leung K, Chen L, Leroy C, Ramakrishna M, Rance R, Lau KW, Mudie LJ, Varela I, McBride DJ, Bignell GR, Cooke SL, Shlien A, Gamble J, Whitmore I, Maddison M, Tarpey PS, Davies HR, Papaemmanuil E, et al: Mutational processes molding the genomes of 21 breast cancers. Cell 2012, 149:979-993.

21. Roberts SA, Lawrence MS, Klimczak L, Grimm SA, Fargo D, Stojanov P, Kiezun A, Kryukov GV, Carter SL, Saksena G, Harris S, Shah RR, Resnick MA, Getz G, Gordenin DA: An APOBEC cytidine deaminase mutagenesis pattern is widespread in human cancers. Nat Genet 2013, 45:970-976.

22. Greenman C, Stephens P, Smith R, Dalgliesh GL, Hunter C, Bignell G, Davies H, Teague J, Butler A, Stevens C, Edkins S, O'Meara S, Vastrik I, Schmidt EE, Avis T, Barthorpe S, Bhamra G, Buck G, Choudhury B, Clements J, Cole J, Dicks E, Forbes S, Gray K, Halliday K, Harrison R, Hills K, Hinton J, Jenkinson $A$, Jones $D$, et al: Patterns of somatic mutation in human cancer genomes. Nature 2007, 446:153-158.

23. Yap TA, Sandhu SK, Carden CP, de Bono JS: Poly(ADP-ribose) polymerase (PARP) inhibitors: exploiting a synthetic lethal strategy in the clinic. $C A$ Cancer J Clin 2011, 61:31-49.

24. Shah SP, Morin RD, Khattra J, Prentice L, Pugh T, Burleigh A, Delaney A, Gelmon K, Guliany R, Senz J, Steidl C, Holt RA, Jones S, Sun M, Leung G, Moore R, Severson T, Taylor GA, Teschendorff AE, Tse K, Turashvili G, Varhol R, Warren RL, Watson P, Zhao Y, Caldas C, Huntsman D, Hirst M, Marra MA, Aparicio S: Mutational evolution in a lobular breast tumour profiled at single nucleotide resolution. Nature 2009, 461:809-813.

25. Roka S, Fiegl M, Zojer N, Filipits M, Schuster R, Steiner B, Jakesz R, Huber H, Drach J: Aneuploidy of chromosome 8 as detected by interphase fluorescence in situ hybridization is a recurrent finding in primary and metastatic breast cancer. Breast Cancer Res Treat 1998, 48:125-133.

26. Park SY, Lee HE, Li H, Shipitsin M, Gelman R, Polyak K: Heterogeneity for stem cell-related markers according to tumor subtype and histologic stage in breast cancer. Clin Cancer Res 2010, 16:876-887.

27. Farabegoli F, Santini D, Ceccarelli C, Taffurelli M, Marrano D, Baldini N: Clone heterogeneity in diploid and aneuploid breast carcinomas as detected by FISH. Cytometry 2001, 46:50-56.

28. Teixeira MR, Pandis N, Bardi G, Andersen JA, Heim S: Karyotypic comparisons of multiple tumorous and macroscopically normal surrounding tissue samples from patients with breast cancer. Cancer Res 1996, 56:855-859.

29. Teixeira MR, Pandis N, Bardi G, Andersen JA, Mitelman F, Heim S: Clonal heterogeneity in breast cancer: karyotypic comparisons of multiple intraand extra-tumorous samples from 3 patients. Int J Cancer 1995, 63:63-68.

30. Gerlinger M, Rowan AJ, Horswell S, Larkin J, Endesfelder D, Gronroos E, Martinez P, Matthews N, Stewart A, Tarpey P, Varela I, Phillimore B, Begum S, McDonald NQ, Butler A, Jones D, Raine K, Latimer C, Santos CR, Nohadani M, Eklund AC, Spencer-Dene B, Clark G, Pickering L, Stamp G, Gore M, Szallasi Z, Downward J, Futreal PA, Swanton C: Intratumor heterogeneity and branched evolution revealed by multiregion sequencing. $N$ Engl J Med 2012, 366:883-892

31. Navin N, Kendall J, Troge J, Andrews P, Rodgers L, Mclndoo J, Cook K, Stepansky A, Levy D, Esposito D, Muthuswamy L, Krasnitz A, McCombie WR, Hicks J, Wigler M: Tumour evolution inferred by single-cell sequencing. Nature 2011, 472:90-94.

32. Roychowdhury $\mathrm{S}$, Iyer MK, Robinson DR, Lonigro RJ, WU YM, Cao X, Kalyana-Sundaram S, Sam L, Balbin OA, Quist MJ, Barrette T, Everett J, Siddiqui J, Kunju LP, Navone N, Araujo JC, Troncoso P, Logothetis CJ, Innis JW, Smith DC, Lao CD, Kim SY, Roberts JS, Gruber SB, Pienta KJ, Talpaz M, Chinnaiyan AM: Personalized oncology through integrative high-throughput sequencing: a pilot study. Sci Transl Med 2011, 3:111ra121.

33. Simon R, Roychowdhury S: Implementing personalized cancer genomics in clinical trials. Nat Rev Drug Discov 2013, 12:358-369.

34. Natrajan R, Wilkerson P: From integrative genomics to therapeutic targets. Cancer Res 2013, 73:3483-3488. 
35. Kumar RD, Chang LW, Ellis MJ, Bose R: Prioritizing potentially druggable mutations with dGene: an annotation tool for cancer genome sequencing data. PLoS One 2013, 8:e67980.

36. Griffith M, Griffith OL, Coffman AC, Weible JV, McMichael JF, Spies NC, Koval J, Das I, Callaway MB, Eldred JM, Miller CA, Subramanian J, Govindan R, Kumar RD, Bose R, Ding L, Walker JR, Larson DE, Dooling DJ, Smith SM, Ley TJ, Mardis ER, Wilson RK: DGldb: mining the druggable genome. Nat Methods 2013, 10:1209-1210.

37. Hopkins AL, Groom CR: The druggable genome. Nat Rev Drug Discov 2002, 1:727-730.

38. Banerji S, Cibulskis K, Rangel-Escareno C, Brown KK, Carter SL, Frederick AM, Lawrence MS, Sivachenko AY, Sougnez C, Zou L, Cortes ML, FernandezLopez JC, Peng S, Ardlie KG, Auclair D, Bautista-Piña V, Duke F, Francis J, Jung J, Maffuz-Aziz A, Onofrio RC, Parkin M, Pho NH, Quintanar-Jurado V, Ramos AH, Rebollar-Vega R, Rodriguez-Cuevas S, Romero-Cordoba SL, Schumacher SE, Stransky N, et al: Sequence analysis of mutations and translocations across breast cancer subtypes. Nature 2012, 486:405-409.

39. Kan Z, Jaiswal BS, Stinson J, Janakiraman V, Bhatt D, Stern HM, Yue P, Haverty PM, Bourgon R, Zheng J, Moorhead M, Chaudhuri S, Tomsho LP, Peters BA, Pujara K, Cordes S, Davis DP, Carlton VE, Yuan W, Li L, Wang W, Eigenbrot C, Kaminker JS, Eberhard DA, Waring P, Schuster SC, Modrusan Z, Zhang Z, Stokoe D, de Sauvage FJ, et al: Diverse somatic mutation patterns and pathway alterations in human cancers. Nature 2010, 466:869-873.

40. Shah SP, Roth A, Goya R, Oloumi A, Ha G, Zhao Y, Turashvili G, Ding J, Tse K, Haffari G, Bashashati A, Prentice LM, Khattra J, Burleigh A, Yap D, Bernard V, McPherson A, Shumansky K, Crisan A, Giuliany R, Heravi-Moussavi A, Rosner J, Lai D, Birol I, Varhol R, Tam A, Dhalla N, Zeng T, Ma K, Chan SK, et al: The clonal and mutational evolution spectrum of primary triple-negative breast cancers. Nature 2012, 486:395-399.

41. Stephens PJ, Tarpey PS, Davies H, Van Loo P, Greenman C, Wedge DC, Nik-Zainal S, Martin S, Varela I, Bignell GR, Yates LR, Papaemmanuil E, Beare D, Butler A, Cheverton A, Gamble J, Hinton J, Jia M, Jayakumar A, Jones D, Latimer C, Lau KW, McLaren S, McBride DJ, Menzies A, Mudie L, Raine K, Rad R, Chapman MS, Teague J, et al: The landscape of cancer genes and mutational processes in breast cancer. Nature 2012, 486:400-404.

42. Lee JW, Soung YH, Seo SH, Kim SY, Park CH, Wang YP, Park K, Nam SW, Park WS, Kim SH, Lee JY, Yoo NJ, Lee SH: Somatic mutations of ERBB2 kinase domain in gastric, colorectal, and breast carcinomas. Clin Cancer Res 2006, 12:57-61.

43. Bose R, Kavuri SM, Searleman AC, Shen W, Shen D, Koboldt DC, Monsey J, Goel N, Aronson AB, Li S, Ma CX, Ding L, Mardis ER, Ellis MJ: Activating HER2 mutations in HER2 gene amplification negative breast cancer. Cancer Discov 2013, 3:224-237.

44. Toy W, Shen Y, Won H, Green B, Sakr RA, Will M, Li Z, Gala K, Fanning S, King TA, Hudis C, Chen D, Taran T, Hortobagyi G, Greene G, Berger M, Baselga J, Chandarlapaty S: ESR1 ligand-binding domain mutations in hormone-resistant breast cancer. Nat Genet 2013, 45:1439-1445.

45. Robinson DR, Wu YM, Vats P, Su F, Lonigro RJ, Cao X, Kalyana-Sundaram S, Wang R, Ning Y, Hodges L, Gursky A, Siddiqui J, Tomlins SA, Roychowdhury S, Pienta KJ, Kim SY, Roberts JS, Rae JM, Van Poznak CH, Hayes DF, Chugh R, Kunju LP, Talpaz M, Schott AF, Chinnaiyan AM: Activating ESR1 mutations in hormone-resistant metastatic breast cancer. Nat Genet 2013, 45:1446-1451.

46. Ellis LM, Fidler IJ: Finding the tumor copycat. Therapy fails, patients don't. Nat Med 2010, 16:974-975.

47. Johnson Jl, Decker S, Zaharevitz D, Rubinstein LV, Venditti JM, Schepartz S, Kalyandrug S, Christian M, Arbuck S, Hollingshead M, Sausville EA: Relationships between drug activity in $\mathrm{NCl}$ preclinical in vitro and in vivo models and early clinical trials. Br J Cancer 2001, 84:1424-1431.

48. Voskoglou-Nomikos T, Pater $J$, Seymour L: Clinical predictive value of the in vitro cell line, human xenograft, and mouse allograft preclinical cancer models. Clin Cancer Res 2003, 9:4227-4239.

49. Jin K, Teng L, Shen Y, He K, Xu Z, Li G: Patient-derived human tumour tissue xenografts in immunodeficient mice: a systematic review. Clin Transl Oncol 2010, 12:473-480.

50. Morton $\mathrm{CL}$, Houghton PJ: Establishment of human tumor xenografts in immunodeficient mice. Nat Protoc 2007, 2:247-250.

51. Rubio-Viqueira B, Hidalgo M: Direct in vivo xenograft tumor model for predicting chemotherapeutic drug response in cancer patients. Clin Pharmacol Ther 2009, 85:217-221.
52. Sausville EA, Burger AM: Contributions of human tumor xenografts to anticancer drug development. Cancer Res 2006, 66:3351-3354. discussion 3354.

53. DeRose YS, Wang G, Lin YC, Bernard PS, Buys SS, Ebbert MT, Factor R, Matsen C, Milash BA, Nelson E, Neumayer L, Randall RL, Stijleman IJ, Welm BE, Welm AL: Tumor grafts derived from women with breast cancer authentically reflect tumor pathology, growth, metastasis and disease outcomes. Nat Med 2011, 17:1514-1520.

54. McEvoy J, Ulyanov A, Brennan R, Wu G, Pounds S, Zhang J, Dyer MA Analysis of MDM2 and MDM4 single nucleotide polymorphisms, mRNA splicing and protein expression in retinoblastoma. PLoS One 2012, 7:e42739.

55. Reyal F, Guyader C, Decraene C, Lucchesi C, Auger N, Assayag F, De Plater L, Gentien D, Poupon MF, Cottu P, De Cremoux P, Gestraud P, Vincent-Salomon A, Fontaine JJ, Roman-Roman S, Delattre O, Decaudin D, Marangoni E: Molecular profiling of patient-derived breast cancer xenografts. Breast Cancer Res 2012, 14:R11.

56. Zhao X, Liu Z, Yu L, Zhang Y, Baxter P, Voicu H, Gurusiddappa S, Luan J, Su $J M$, Leung HC, Li XN: Global gene expression profiling confirms the molecular fidelity of primary tumor-based orthotopic xenograft mouse models of medulloblastoma. Neuro Oncol 2012, 14:574-583.

57. Ng S, Collisson EA, Sokolov A, Goldstein T, Gonzalez-Perez A, Lopez-Bigas N, Benz C, Haussler D, Stuart JM: PARADIGM-SHIFT predicts the function of mutations in multiple cancers using pathway impact analysis. Bioinformatics 2012, 28:i640-i646

58. Vaske CJ, Benz SC, Sanborn JZ, Earl D, Szeto C, Zhu J, Haussler D, Stuart JM: Inference of patient-specific pathway activities from multi-dimensional cancer genomics data using PARADIGM. Bioinformatics 2010, 26:i237-245.

59. Tabchy A, Hennessy BT, Gonzalez-Angulo AM, Bernstam FM, Lu Y, Mills GB: Quantitative proteomic analysis in breast cancer. Drugs Today (Barc) 2011, 47:169-182.

60. Ellis MJ, Gillette M, Carr SA, Paulovich AG, Smith RD, Rodland KK, Townsend RR, Kinsinger C, Mesri M, Rodriguez H, Liebler DC, Clinical Proteomic Tumor Analysis Consortium (CPTAC): Connecting genomic alterations to cancer biology with proteomics: the $\mathrm{NCl}$ Clinical Proteomic Tumor Analysis Consortium. Cancer Discov 2013, 3:1108-1112.

\section{doi:10.1186/s13058-014-0460-4}

Cite this article as: Goncalves et al: New concepts in breast cancer genomics and genetics. Breast Cancer Research 2014 16:460. 